\title{
Growth kinetics of GaN thin films grown by OMVPE using single source precursors
}

R. A. Fischer*, A. Wohlfart, A. Devi, and W. Rogge

*Anorganische Chemie II, Ruhr Universtität Bochum, D-44801, Germany

\begin{abstract}
We report the growth kinetics of GaN thin films using the single source precursor bisazido dimethylaminopropyl gallium (BAZIGA) in a cold wall reactor. Transparent, smooth, epitaxial (FWHM of the $\alpha-\mathrm{GaN} 0002$ rocking curve $=129.6 \mathrm{arcsec}$ ) and stoichiometric $\mathrm{GaN}$ films were grown on c-plane $\mathrm{Al}_{2} \mathrm{O}_{3}$ substrates in the temperature range of $870-1320 \mathrm{~K}$ and high growth rates were obtained (up to $4000 \mathrm{~nm} / \mathrm{hr}$ ). Film growth was studied as a function of substrate temperature as well as reactor pressure. Although high quality films were obtained without using any additional source of nitrogen such as ammonia, we have investigated the effect of ammonia on the growth and properties of the resulting films. The films obtained were characterized by XRD, RBS, XPS, AES, AFM, SEM and the room temperature PL spectroscopy of GaN films grown exhibited the correct near band edge luminescence at $3.45 \mathrm{eV}$.
\end{abstract}

\section{INTRODUCTION}

The nitrides GaN, AlN, InN and their ternary alloy systems AlGaN and InGaN are very promising materials for applications in green/blue light-emitting diodes and semicon-ductor lasers ${ }^{[1]}$. The commercial growth of high quality epitaxial group- 13 nitrides by organometallic vapor phase epitaxy (OMVPE) is based on the co-pyrolysis of metal alkyls $\mathrm{MR}_{3}\left(\mathrm{M}=\mathrm{Al}, \mathrm{Ga}\right.$, In, $\left.\mathrm{R}=\mathrm{CH}_{3}, \mathrm{C}_{2} \mathrm{H}_{5},{ }^{\mathrm{t}} \mathrm{Bu}\right)$ and $\mathrm{NH}_{3}$. But high temperatures are involved in this process for the effective activation of $\mathrm{NH}_{3}\left(>773 \mathrm{~K}\right.$ for $\mathrm{InN}^{[2]},>1173 \mathrm{~K}$ for $\mathrm{AlN}$ and $\mathrm{GaN}^{[3]}$ ).

Many efforts have been undertaken to substitute the ineffective nitrogen source $\left(\mathrm{NH}_{3}\right)$ using alternative precursors based on the concept of preformed direct $\mathrm{M}-\mathrm{N}$ bonds in the precursor molecule. Such precursors for the growth at a lower V/III ratio and milder growth conditions were achieved with many compounds for instance hydrazine $\left(\mathrm{N}_{2} \mathrm{H}_{4}\right)$, 1-1-dimethyl hydrazine $\left(\mathrm{M}_{2} \mathrm{NNH}_{2}\right)$, phenyl hydrazine $\left(\mathrm{PhNH}-\mathrm{NH}_{2}\right)$, hydrazoic acid $\left(\mathrm{HN}_{3}\right)^{[6-8]}$ and also alkyl amines $\left(\mathrm{RNH}_{2}, \mathrm{R}={ }^{\mathrm{t}} \mathrm{Bu},{ }^{\mathrm{i}} \mathrm{Pr}\right)^{[9]}$. But the disadvantages of these precursors are their toxic and explosive nature as well as carbon incorporation into the resulting films. Besides these compounds, some group-III metal amido compounds such as $\left[\mathrm{R}_{2} \mathrm{GaNH}_{2}\right]_{3}(\mathrm{R}=\mathrm{Et}, \mathrm{Me})$ and $\left[\mathrm{Ga}\left(\mathrm{NR}_{2}\right)_{3}\right]_{2}(\mathrm{R}=\mathrm{Et}, \mathrm{Me})$ are interesting as single source precursors (SSP). However these precursors are only used with limited success in terms of the achieved film properties ${ }^{[10]}$. The azides such as $\left[\mathrm{R}_{2} \mathrm{GaN}_{3}\right]_{\mathrm{x}}(\mathrm{R}=\mathrm{Cl}, \mathrm{H}, \mathrm{Et}$, $\mathrm{Me}$ ) are possible candidates as SSP and have been already used successfully to grow $\mathrm{GaN}^{[11]}$. The azide group combines a pre-formed strong $\mathrm{Ga}-\mathrm{N}$ bond with a reduced number of undesired $\mathrm{Ga}-\mathrm{C}$ and $\mathrm{N}-\mathrm{C}$ bonds to minimize the carbon incorporation during film growth. But the disadvantage with these precursors are their air sensitivity and explosivity. To find an alternative to these problems we concentrated our research on the growth 
of epitaxial GaN films using the novel Lewis-base stabilized organometallic azide compound of the type $\left(\mathrm{N}_{3}\right)_{\mathrm{a}} \mathrm{M}\left[\left(\mathrm{CH}_{2}\right)_{3} \mathrm{NMe}_{2}\right]_{3-\mathrm{a}}(\mathrm{M}=\mathrm{Al}, \mathrm{Ga}$, In and $\mathrm{a}=1,2)$. These SSP's are non-pyrophoric, non-explosive and yield epitaxial $\mathrm{GaN}$ films under moderate conditions. The successful growth of GaN and InN films was already reported earlier using a simple horizontal hot wall CVD reactor ${ }^{[12-14]}$. In this paper we report the study on the growth kinetics of $\mathrm{GaN}$ from the precursor $\left(\mathrm{N}_{3}\right)_{2} \mathrm{Ga}\left[\left(\mathrm{CH}_{2}\right)_{3} \mathrm{NMe}_{2}\right]$ (bisazido dimethylaminopropyl gallium, BAZIGA) in a horizontal cold wall CVD reactor.

\section{EXPERIMENT}

For GaN film deposition, a horizontal low pressure cold wall CVD reactor (base pressure: $10^{-6}$ Torr) was fabricated (Fig. 1). It consists of a quartz tube about $50 \mathrm{~cm}$ in length and $2.5 \mathrm{~cm}$ in diameter. The substrates are placed on a SiC coated graphite susceptor at the center of the tube. For the substrate heating, an inductive heating arrangement was used monitored by a radiation pyrometer. During the heating process the outer wall of the central part of the quartz tube was cooled by water. Using this set up temperatures up to $1473 \mathrm{~K}$ could be attained. Attached to the quartz tube are the precursor vaporizer heated by means of an air bath and a glas trap cooled with liquid nitrogen. To generate the necessary vacuum, a turbo-molecular pump backed up by a rotary pump was used. The reactor pressure during the CVD process was regulated using a motor driven throttle valve and mass flow controllers were used to control the flow of different gases. For $\mathrm{GaN}$ film deposition, epi-polished c-plane $\mathrm{Al}_{2} \mathrm{O}_{3}$ substrates as large as $1 \mathrm{x} 1 \mathrm{~cm}$ were used. Before loading it into the reactor, the substrates were degreased in trichloroethylene, etched in a mixture of $\mathrm{H}_{2} \mathrm{SO}_{4} / \mathrm{H}_{3} \mathrm{PO}_{4}(3: 1)$ at $353 \mathrm{~K}$ and rinsed with water and acetone. After the etching and cleaning process the substrates were pre-treated under vacuum for several hours $(12 \mathrm{~h})$ and subsequently annealed at $1323 \mathrm{~K}$ with hydrogen $(10 \mathrm{sccm})$ for 1 hour. Following this annealing, the substrates were nitridated with ammonia (40 $\mathrm{sccm})$ at $1223 \mathrm{~K}$ for $30 \mathrm{~min}$. The vaporizer temperature was maintained at $353 \mathrm{~K}$ for all depositions. Finally the vaporizer valve was opened to start the deposition which lasted normally for $45 \mathrm{~min}$. High purity nitrogen $(40 \mathrm{sccm})$ was used as a carrier gas to transport the precursor to the reaction zone. The deposition temperature was varied in the range of

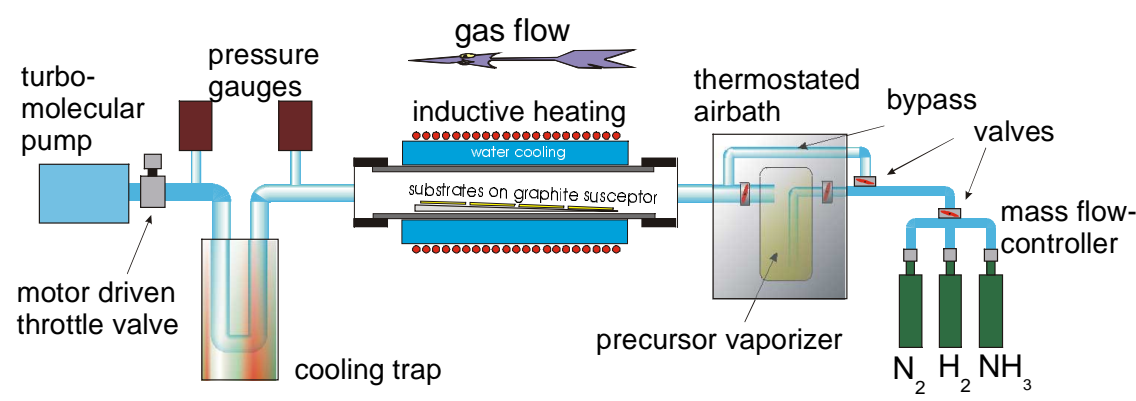

Fig. 1) Schematic of the cold wall CVD reactor 
$773-1323 \mathrm{~K}$, the reactor pressure between $0.080-100.0$ mbar. To investigate the influence of ammonia as a reactive gas to the growth process, ammonia flow rates were varied at different temperatures and pressures. The crystalline properties of the obtained films were investigated in detail by $\mathrm{x}$-ray diffraction studies using a D8-Advance Bruker axs diffractometer and a high resolution D8-Discover Bruker axs diffractometer. The $2 \Theta-\Theta$ scans, rocking curves, pole figures, reciprocal space mappings and reflectometry measurements were carried out. The film composition was determined by Rutherford Back Scattering (RBS) using the instrument of DTL (Dynamitron Tandem Laboratory), X-ray Photoelectron Spectroscopy (XPS) as well as Auger Electron Spectroscopy (AES) using the equipment from FISONS. The optical properties were studied by room temperature Photoluminescence (PL). The surface morphology was investigated with Atomic Force Microscopy (AFM) using a Nanoscope Multimode III scanning probe microscope (Digital Instruments) and Scanning Electron Microscopy (SEM) using an equipment from LEO. The film thickness was analyzed by AFM, using a TOPOMETRIX mircoscope.

\section{RESULTS AND DISCUSSION}

The primary goal was to grow epitaxial GaN films using BAZIGA with $\mathrm{N}_{2}$ as inert carrier gas but without any additional nitrogen source such as ammonia. In fact this was achieved successfully. The films were grown without any buffer layers except that the substrates were nitridated with ammonia. It was found that at temperatures below $973 \mathrm{~K}$ the films were predominantly amorphous. X-ray diffractograms showed a broad $0002 \alpha$ $\mathrm{GaN}$ reflection with low intensity. At higher temperatures crystalline $\alpha-\mathrm{GaN}$ was found with a sharp $0002 \alpha-\mathrm{GaN}$ reflection and high intensity. It was also found that the crystal quality and the signal intensity was clearly improved with increasing pressure due to the decreasing growth rate. At low reactor pressures $(0.080 \mathrm{mbar})$ growth rates of the order of $4500 \mathrm{~nm} / \mathrm{hr}$ were obtained whereas higher reactor pressures $(8.000 \mathrm{mbar})$ resulted in growth rates of the order of $2000 \mathrm{~nm} / \mathrm{hr}$. Besides the reactor pressure, the growth rate

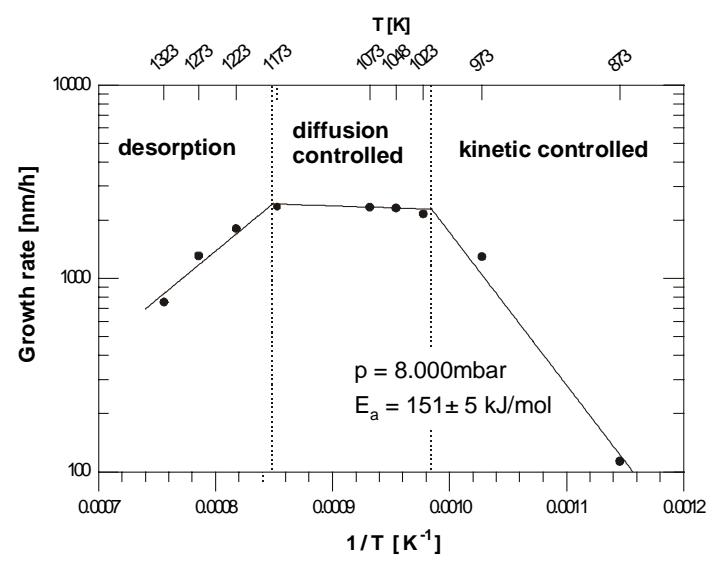

Fig. 2) Arrhenius-plot at 8.000 mbar without $\mathrm{NH}_{3}$ strongly depends on the substrate temperature because of surface reactions and altered reaction pathways. From the Arrheniusplot (Fig. 2) the temperature dependence of the growth rate can be clearly seen. The growth rate at lower temperatures indicates a thermally activated deposition kinetics. To determinate the activation energy $\left(E_{a}\right)$ for the linear portion of the curve in the kinetic controlled part at lower temperatures, the Arrhenius equation $\mathrm{G}=\mathrm{A} \cdot \exp \left(-\mathrm{E}_{\mathrm{a}} / \mathrm{RT}\right)$ 
was used, where $\mathrm{G}$ is the growth rate, $\mathrm{A}$ is the Arrhenius pre-exponential factor, $\mathrm{R}$ is the gas constant and $\mathrm{E}_{\mathrm{a}}$ the activation energy that is the rate limitting process under the given conditions. For all depositions a reactor pressure of 8.000 mbar was adjusted. It was found that in the temperature range of $870-1020 \mathrm{~K}$ the GaN film growth is associated with an activation energy of $151 \pm 5 \mathrm{~kJ} / \mathrm{mol}$. The maximum growth rate of $2500 \mathrm{~nm} / \mathrm{h}$ was obtained in the temperature range of $1020-1175 \mathrm{~K}$. In this range, the growth rate shows nearly no temperature dependence that means the growth is only controlled by the diffusion of the precursor molecule fragments to the substrate surface. At temperatures over $1175 \mathrm{~K}$ the growth rate decreases because of desorption and depletion processes consistent with the typical behavior of a CVD process. To investigate the influence of ammonia as a reactive gas to the growth kinetics, an Arrhenius-plot under the same conditions (8.000 mbar reactor pressure and $363 \mathrm{~K}$ vaporizer temperature) but with additional $\mathrm{NH}_{3}(40 \mathrm{sccm})$ was carried out. Under these conditions some differences were observed and it was found that the slope of the kinetically controlled regime is lowered by more than half yielding an activation energy of $\mathrm{E}_{\mathrm{a}}=65 \pm 5 \mathrm{~kJ} / \mathrm{mol}$. A temperature range of $870-1060 \mathrm{~K}$ for the kinetically controlled regime was obtained. Thereby the kinetically controlled regime is extended to higher temperatures than in the previous case where no $\mathrm{NH}_{3}$ was used. The growth rate was also reduced and the highest growth rate of the order of $1000 \mathrm{~nm} / \mathrm{h}$ was obtained in the range of $1060-1175 \mathrm{~K}$. The growth rate drops off again at temperatures greater than $1175 \mathrm{~K}$. In addition to the reduction in $\mathrm{E}_{\mathrm{a}}$ and growth rates, the crystalline quality of the resulting films were poorer when compared to those obtained without $\mathrm{NH}_{3}$ under similar CVD conditions. To study the effect of $\mathrm{NH}_{3}$ on the crystalline quality, several $\alpha-\mathrm{GaN}$ films were deposited at a reactor pressure of 8.000 mbar and a substrate temperature of $1073 \mathrm{~K}$ with increasing ammonia flow. The film properties were determined with x-ray diffraction (XRD) and it was found that the obtained films were epitaxial due to the fact that the diffractograms showed only the 0002 reflection and also confirmed from their pole figure measurements (Fig. 4). To investigate the crystalline quality, rocking curves of the $0002 \alpha-\mathrm{GaN}$ reflection have been carried out. Fig. 3 shows the variation of FWHM (as determined by x-ray rocking curves) of the epitaxial $\alpha-\mathrm{GaN}$ films with increasing ammonia flow rates. It is to be noted that the FWHM of the $0002 \mathrm{GaN}$ rocking curves strongly depends on the flow rate of $\mathrm{NH}_{3}$. With

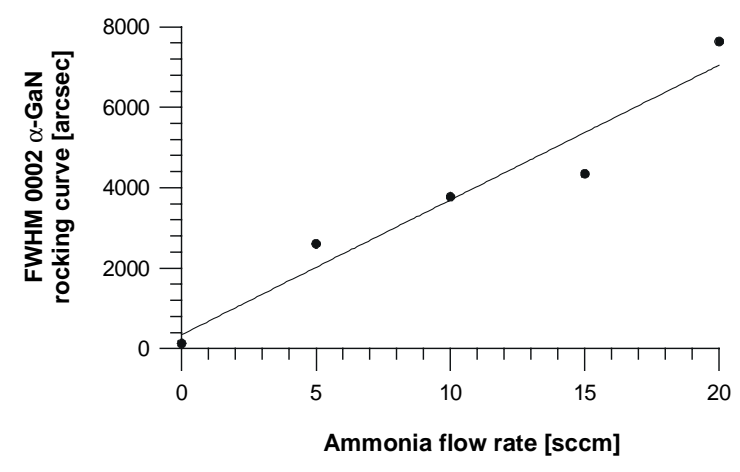

Fig. 3) Variation of FWHM with $\mathrm{NH}_{3}$ flow rates increasing $\mathrm{NH}_{3}$ flow, the FWHM increases. Without ammonia a FWHM of 129.6 arcsec was achieved. This is to our knowledge the best ever reported value for the epitaxial films obtained from single source precursors without any additional source for nitrogen. As illustrated in Fig. 3, with increasing ammonia flow rates, the crystal quality becomes poorer. The pole figure measurement (Fig. 4) was 

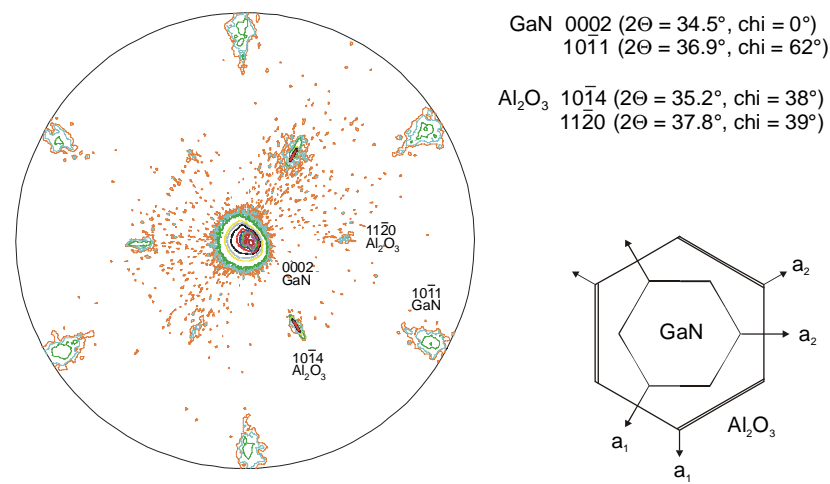

setup with a fixed $2 \Theta$ value of $34.5^{\circ}$ and $\omega=17.25^{\circ}$ and $\psi=0-65^{\circ}, \phi$ $=0-360^{\circ}$. The $2-$ dimensional plot shows both the reflections from $\alpha-\mathrm{GaN}(0002)$ and $(10 \overline{1} 1)$ and from the $\mathrm{Al}_{2} \mathrm{O}_{3}$ substrate $(10 \overline{1} 4)$ and $(11 \overline{2} 0)$ at different $\psi$ and $\phi$ angles. From these reflections the orientation of

Fig. 4) Pole figure measurement and orientation of a $\alpha-G a N$ film

the $\alpha$-GaN layer relative to the sapphire substrate could be determined as $30^{\circ}$. By means of these pole figure measurements as well as $2 \Theta-\Theta$ scans and reciprocal space mappings the hexagonal symmetry of the produced $\mathrm{GaN}$ films was confirmed.

To investigate the role of substrate nitridation, two amorphous low temperature films (grown at $773 \mathrm{~K}$ and 8.000 mbar) were characterized by $\mathrm{x}$-ray reflectometry. It was seen that during the nitridation of the bare $\mathrm{Al}_{2} \mathrm{O}_{3}$ substrates with $\mathrm{NH}_{3}$ for $30 \mathrm{~min}$, a thin layer of AlN $(0.5 \mathrm{~nm})$ was formed and this was verified by XPS measurements. The absence of the AIN layer on a non-nitridated $\mathrm{Al}_{2} \mathrm{O}_{3}$ substrate was also verified by XPS. The density of the grown $\alpha-\mathrm{GaN}$ layer was found to be significantly lower $\left(4.42 \mathrm{~g} / \mathrm{cm}^{3}\right)$ than crystalline bulk $\alpha-\mathrm{GaN}\left(6.1 \mathrm{~g} / \mathrm{cm}^{3}\right)$. This could be caused by incorporation of residual precursor fragments as well as structural defects. The roughness of the GaN layer was determined as $\sim 1 \mathrm{~nm}$ from reflectometry. This was also confirmed by AFM measurements. Crystalline high temperature films could not be characterized by x-ray reflectometry because of their higher surface roughness. The film composition was checked with RBS and XPS including nitrogen, gallium, carbon and oxygen to determine the Ga-N stoichiometry as well as the level of impurity. The RBS analysis revealed stoichiometric GaN in a "chemical sense" with a ratio of $\mathrm{Ga}$ and $\mathrm{N}$ of 1:1 without any additional oxygen. To determine possible impurities the films were analyzed by XPS. It was found that GaN films, grown at $973 \mathrm{~K}$, contained very small traces of carbon when grown without using ammonia and this can be accounted due to the fragmentation of the precursor leading to carbon incorporation. Whereas in $\mathrm{GaN}$ films grown at $1173 \mathrm{~K}$ at 8.000 mbar reactor pressure and $363 \mathrm{~K}$ vaporizer temperature with $20 \mathrm{sccm} \mathrm{NH}_{3}$, carbon was absent (Fig. 5). It was found that very small amounts of ammonia were necessary to grow $\mathrm{GaN}$ films free of carbon.

\section{CONCLUSIONS}

It was demonstrated that it is possible to grow GaN films using BAZIGA as a single source precursor without any additional nitrogen source such as $\mathrm{NH}_{3}$ with a high structural quality which is reasonable close to the materials grown with the standard process 


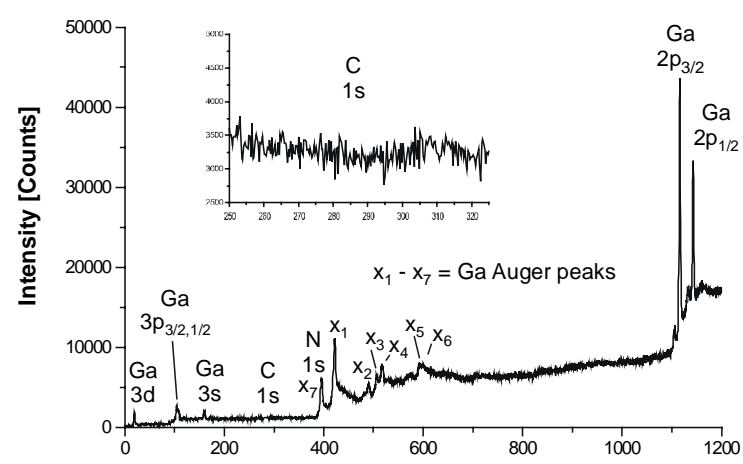

Fig. 5) XPS spektrum of a GaN film and exhibiting the characteristic band edge luminescence of 3.45 $\mathrm{eV}$. The use of $\mathrm{NH}_{3}$ during the deposition has an important influence to the resulting film properties. It was found that the best crystalline $\alpha$-GaN films were achieved at higher reactor pressures (above 10 mbar) without using any $\mathrm{NH}_{3}$. In this case very small traces of carbon could be found by XPS. Moreover using very

low flow rates of $\mathrm{NH}_{3}(2-5 \mathrm{sccm})$ during deposition, the carbon incorporation was eliminated, but with increasing $\mathrm{NH}_{3}$ flow rates (up to $20 \mathrm{sccm}$ ) the crystalline quality decreased drastically.

\section{ACKNOWLEDGMENTS}

The authors thank the Deutsche Forschungsgemeinschaft (DFG) for financial support. A. D. thanks the Alexander von Humboldt foundation, Germany for a fellowship.

\section{REFERENCES}

[1] S. Nakamura, MRS Bulletin 23, 1998, 37.

[2] C. R. Eddy, T. D. Moustakas, J. Appl. Phys. 73, 1993, 448.

[3] S. Strite, H. Morkoç, J. Vac. Sci. Technol. B10, 1992, 1237.

[4] D. Gaskill, N. Bottka, M. C. Lin, Appl. Phys. Lett. 48, 1986, 1449.

[5] S. Miyoshi, K. Onabe, N. Ohkouchi, H. Yaguchi, R. Ito, S. Fukatsu, S. Yoshida, J. Cryst. Growth 124, 1992, 439.

[6] H. Okumura, S. Misawa, T. Okahisa, S. Yoshida, J. Cryst. Growth 136, 1994, 361.

[7] D. G. Chtchkine, L. P. Fu, G. D. Gilliland, Y. Chen, S. E. Ralph, K. K. Bajaj, Y. Bu, M. C. Lin, J. Chem. Soc. 42, 1995, 423.

[8] C. J. Linnen, R. D. Coombe, Appl. Phys. Lett. 72, 1998, 88.

[9] B. Beaumont, P. Gilbart, J. P. Faurie, J. Cryst. Growth 156, 1995, 140.

[10] A. C. Jones, S. A. Rushworth, D. J. Houlton, J. S. Roberts, V. Roberts, C. R. Whitehouse, G. W. Critchlow, Chem. Vap. Dep. 2, 1996, 5.

[11] H. S. Park, S. D. Waezsada, A. H. Cowley, H. W. Roesky, Chem. Mater. 10, 1998, 2251.

[12] R. A. Fischer, A. Miehr, O. Ambacher, T. Metzger, E. Born, J. Cryst. Growth 170, 1997, 139.

[13] R. A, Fischer, H. Sussek, H. Pritzkow, E. Herdtweck, J. Organomet. Chem. 548, 1997, 73

[14] A. Devi, W. Rogge, R. A. Fischer, F. Stowasser, H. Sussek, H. W. Becker, J. Schäfer, J. Wolfrum, J. Phys. IV France 9, 1999, 589 